\title{
Geographical variation in spawning histories of age-1 Pacific saury Cololabis saira in the North Pacific Ocean during June and July
}

\author{
Satoshi Suyama ${ }^{1} \cdot$ Hitomi Ozawa $^{2,4} \cdot$ Yasutoki Shibata $^{1} \cdot$ Taiki Fuji $^{1,5} \cdot$ Masayasu Nakagami $^{1,6} \cdot$ Akio Shimizu $^{3}$
}

Received: 23 August 2018 / Accepted: 24 February 2019 / Published online: 27 March 2019

(C) The Author(s) 2020, corrected publication 2020

\begin{abstract}
We examine geographical differences in percentages of age-1 Pacific saury Cololabis saira with previous spawning experience collected from $143^{\circ} \mathrm{E}$ to $165^{\circ} \mathrm{W}$ during June and July of 2013 and 2014. Previous spawning experience of fish was determined using a new histological method involving Victoria blue (VB)-positive ovarian arterioles. We also compared the radius of the otolith annual ring (ROA), which indicates fish body size at the beginning of the breeding season, with the incidence of previous spawning experience. A generalized linear model was used that treats the occurrence of fish with VBpositive arterioles as a response variable, following the Bernoulli distribution of probability $p_{i}$, where longitude, latitude, body length, ROA in age-1 fish, year (2013 or 2014), sea surface temperature, and days elapsed from a survey starting date, are used as fixed effect terms. An estimated regression coefficient of longitude was negative while that of ROA was positive, meaning that the probability of previous spawning increases with a latitudinal progression west, and with increased ROA. Our results suggest that differences in the percentage of previously spawned fish in different geographic areas are caused by differences in body length at the beginning of the breeding season.
\end{abstract}

Keywords Age $\cdot$ Otolith $\cdot$ Spawning experience $\cdot$ Arterioles $\cdot$ Ovary $\cdot$ North Pacific Ocean

Satoshi Suyama

suyama@affrc.go.jp

1 Tohoku National Fisheries Research Institute, Japan Fisheries Research and Education Agency, Hachinohe Station, 25-259, Shimomekurakubo, Same, Hachinohe, Aomori 031-0841, Japan

2 Faculty of Fisheries Sciences, Hokkaido University, 3-1-1, Minato, Hakodate, Hokkaido 988-8501, Japan

3 National Research Institute of Fisheries Science, Japan Fisheries Research and Education Agency, 2-12-4 Fukuura, Yokohama, Kanagawa 236-8648, Japan

4 Present Address: Ministry of Agriculture, Forestry and Fisheries, 1-2-1, Kasumigaseki, Chiyoda,

Tokyo 100-8950, Japan

5 Present Address: The National Research Institute of Far Seas Fisheries, Japan Fisheries Research and Education Agency, 2-12-4 Fukuura, Yokohama, Kanagawa 236-8648, Japan

6 Present Address: National Research Institute of Fisheries Science, Japan Fisheries Research and Education Agency, 2-12-4 Fukuura, Yokohama, Kanagawa 236-8648, Japan

\section{Introduction}

Pacific saury Cololabis saira are widely distributed in subarctic to subtropical regions of the North Pacific Ocean, from the coast of Japan to the western coastal waters of North America (Hubbs and Wisner 1980). This species is caught commercially by Japan, Russia, Korea, China, Taiwan, and Vanuatu, with total landings fluctuating over the last 20 years from 180,973 tons in 1998 to 631,094 tons in 2014 [The Food and Agriculture Organization; http://www. fao.org/fi/statist/statist.asp (Accessed 1 November 2018)]. Prior to 2000, the catch by Japan accounted for more than $80 \%$ of the total world catch, but this has since dropped to approximately $30 \%$ given increased recent foreign catches, concomitant with an expansion of fishing grounds and periods. Japanese and Russian fishing vessels mainly catch Pacific saury in their exclusive economic zone from August to December, whereas Taiwanese, Chinese and Korean fishing vessels operate in more eastern areas, mainly in the high seas west of $165^{\circ} \mathrm{E}$ from June to December (Huang et al. 2007; Huang 2010; Tseng et al. 2013, 2014). 
Improved international management of Pacific saury resources is increasingly necessary. Age at maturity data are important for fisheries management (e.g., DomínguezPetit et al. 2017), but they are difficult to obtain for Pacific saury. This species has a short 2-year life span, with age-1 fish developing an annual ring that forms mainly in winter (Hotta 1960; Suyama 2002). The body length frequency distributions and age composition of caught fish fluctuate annually (Suyama et al. 2006). Spawning occurs over a long time and wide area (Watanabe and Lo 1989), with a breeding season that extends over 10 months from September to June. Spawning grounds shift with season; spawning occurs from the Oyashio-Kuroshio transitional waters off northeastern Japan in autumn and in spring, but moves to the Kuroshio Current region in winter (Watanabe and Lo 1989). Fish spawn multiple times and have asynchronous oocyte development (oocytes in many stages of development occur simultaneously in active ovaries) (Hatanaka 1955; Kosaka 2000; Suyama 2002; Kurita 2006; Suyama et al. 2016a). Rearing experiments suggest the spawning period of an individual fish extends for a maximum of 6 months (Suyama et al. 2016a). Hereafter, we describe the spawning duration for the population of Pacific saury as the 'breeding season,' and the spawning duration for each individual as the 'spawning period.'

Because of differences in the spawning period of individuals, fish that are about to spawn, are spawning, and those that have recently spawned (which cannot readily be distinguished from immature fish) can all be collected in the same month (Kurita 2006). To clarify maturation rate based on the occurrence of spawning fish, extensive investigations over a long period of time are required. However, in a species with a breeding season lasting 10 months, with a spawning ground spread over a wide area throughout the North Pacific Ocean, this is very difficult.

Spawning fish body length (BL), the distance from the tip of the lower jaw to the posterior end of the muscular knob on the caudal peduncle (Kimura 1956), varies in different spawning areas and breeding seasons (Hotta 1960; Kosaka 2000; Sugama 1957). The minimum BL of spawning fish collected from Japanese fishing grounds is about $25 \mathrm{~cm}$ (Hatanaka 1955); however, individuals collected outside the fishing grounds or season can spawn at about $20 \mathrm{~cm}$ (Hotta 1960; Kosaka 2000; Sugama 1957). Based on their body length, these smaller fish could be age- 0 (Kurita et al. 2004; Nakaya et al. 2010; Nemoto et al. 2001; Suyama et al. 1992, 1996, 2011; Watanabe et al. 1988) — that is, they have commenced spawning within 1 year of hatching. Minimum maturation size seems to vary according to spawning area and month. Some fish do commence first spawning in the latter half of age-0 (Hatanaka 1955; Kosaka 2000), but it is not known whether all or only some individuals of this age spawn. If fish do not commence first spawning during this breeding season, they would do so in the next breeding season. As Pacific saury growth varies in different locations (Suyama et al. 2012a) and hatch periods (Kurita et al. 2004; Nemoto et al. 2001), maturation rate in each age-class might be influenced by several factors, such as growth rate, hatch period, or location. We consider the hatching period, growth rate, and age at first spawning to be very closely related in Pacific saury, but the fact that spawning occurs over such a long period and wide area made it difficult to determine exactly how these three factors were related.

Species like Pacific saury with asynchronous oocyte development have postovulatory follicles (POF) or atretic oocytes that originate from yolked oocytes during or after spawning (Barbieri et al. 1994; Hunter and Macewicz 1985a, b; Hunter et al. 1986; Karlou-Riga and Panas 1996; Suyama et al. 2016a), which might provide evidence of previous spawning activity. However, these spawning indicators typically disappear immediately or soon after spawning. For example, POF in anchovy disappear within days, and atretic yolked oocytes within weeks, limiting the use of either to identify previous spawning experience in any individual. However, females of Pacific saury that had spawned up to 6 months previously, that had completely resorbed their POF or atresia oocyte from the yolked oocyte, retained Victoria blue (VB)-positive arterioles in their ovaries, whereas fish that had not spawned did not (Suyama et al. 2016a). As such, VB staining might enable identification of maturation rate in asynchronous spawning fish like Pacific saury.

The Tohoku National Fisheries Research Institute (TNFRI) has routinely performed stock assessment surveys from near the coast of Japan to $165^{\circ} \mathrm{W}$ during the months of June and July (Suyama et al. 2016b). Pacific saury occur widely throughout the survey area during this time, after which age-1 fish commence a westward migration, with most reaching the Japanese fishing ground east of $150^{\circ} \mathrm{E}$ in the fishing season from August to December (Suyama et al. 2012b, Miyamoto et al. 2019). During two of these surveys (2013 and 2014) we collected and examined ovaries of Pacific saury from over a wide geographic area, and for each fish determined the presence or absence of VB-positive arterioles. Collecting Pacific saury during these surveys enabled collection of individuals from the western half of this species' distribution, for it is otherwise more widely distributed throughout the year (Suyama et al. 2012a, b); no comparable opportunity exists for us to collect specimens over such a large area, within such a short period of time. Additionally, the months during which these surveys occurred corresponded with the end of the Pacific saury breeding season, when all fish that would have matured in the current breeding season have or are in the process of finishing spawning. Using these collections, we inferred the percentage of fish that had spawned in the first breeding season, their geographical variation, and differences in their 
size at the beginning of the breeding season, based on otolith annual ring radius details.

\section{Materials and methods}

\section{Trawl survey}

Pacific saury were collected between $143^{\circ} \mathrm{E}$ and $165^{\circ} \mathrm{W}$ using surface trawl nets towed from RV Hokko-maru $\left(143-163^{\circ} \mathrm{E}\right)$ and the training vessel Hokuho-maru $\left(167^{\circ} \mathrm{E}-165^{\circ} \mathrm{W}\right)$ during June and July of 2013 and 2014. The surface trawl (NST-99) was manufactured by Nichimo Co. Ltd. Net width during trawling on Hokuho-maru was $24.0 \mathrm{~m}$, and on Hokko-maru $34.7 \mathrm{~m}$; headline height varied between 20 and $25 \mathrm{~m}$; net length was $90 \mathrm{~m}$; maximum and minimum stretched mesh sizes were $15,189 \mathrm{~mm}$ and $16.7 \mathrm{~mm}$, with a innner cod-end mesh-size of $18 \mathrm{~mm}$ (Ueno et al. 2017). The entire head rope, including wingtips, floated near the surface; the net was towed at 4-5 knots for $1 \mathrm{~h}$ during daytime. Samples were collected from $124\left(36^{\circ} 09-48^{\circ} 35^{\prime} \mathrm{N}\right.$ and $\left.143^{\circ} 09^{\prime} \mathrm{E}-164^{\circ} 58^{\prime} \mathrm{W}\right)$ stations in 2013 and $121\left(37^{\circ} 01-46^{\circ} 24^{\prime} \mathrm{N}\right.$ and $\left.143^{\circ} 58^{\prime} \mathrm{E}-164^{\circ} 58^{\prime} \mathrm{W}\right)$ stations in 2014. The survey region was divided into six areas each spanning $10^{\circ}$ of longitude: $140^{\circ} \mathrm{E}-150^{\circ} \mathrm{E}$, $150^{\circ} \mathrm{E}-160^{\circ} \mathrm{E}, 160^{\circ} \mathrm{E}-170^{\circ} \mathrm{E}, 170^{\circ} \mathrm{E}-180^{\circ}, 180^{\circ}-170^{\circ} \mathrm{W}$, and $170^{\circ} \mathrm{W}-160^{\circ} \mathrm{W}$; these were denoted A140E, A150E, A160E, A170E, A170 W, and A160 W, respectively (Table 1, Fig. 1).

Fish were sorted from the catch, immediately frozen, and transported to the laboratory. BL was measured to the nearest $0.1 \mathrm{~cm}$. When the total number of fish caught at a station was less than 100, all fish were measured; otherwise a random sample (100-434 fish) was measured. From these results and the ratio of the total number of caught fish and the number of measured fish, total catch in each $0.5-\mathrm{cm}$ size class at each sampling station and longitudinal area was estimated. When the total number of Pacific saury caught at any station was less than 80 , all fish was sexed, and for females the ovarian weights (OW) were measured to the nearest $0.01 \mathrm{~g}$; otherwise a random sample of 80 fish was sorted from the catch, measured and sexed, and the OW of any females weighed (Table 1).

\section{Age determination and otolith radius measurement}

After measuring BL, otoliths were extracted. The right otolith was embedded in epoxy resin and the incidence of an annual ring determined using light microscopy following Suyama et al. (2012a, b). Because formation of the annual ring commences in September (Suyama et al. 2011) and is completed by the spring of the following year, during our survey period age-1 fish already had an annual ring (Suyama et al. 2012a, b). After annual ring identification, the radius of the ring (ROA) was measured from the otolith core to the area where ring formation commenced. Otolith images were captured on a computer at $32 \times$ magnification; the ROA was calculated using image analysis software (Image $\times$ Earth 3.0, Kikuchi Optical Co. Ltd., Nagano, Japan). The breeding season started in September (Watanabe and Lo 1989), ROA is an indicator of $\mathrm{BL}$ at the beginning of the breeding season.

\section{Ovary samples}

As BL of both age-1 fish in June and July (Suyama et al. $2012 \mathrm{~b}$ ) and spawning individuals usually exceeded $25 \mathrm{~cm}$, the ovaries that we collected were mainly from age- 1 fish. However, ovaries from some age- 0 fish less than $25 \mathrm{~cm}$ were also collected, as we could not discount the possibility that these fish had previous spawning experience. In total, ovaries from 622 fish from 25 sampling stations $\left(40^{\circ} 53-48^{\circ} 35^{\prime} \mathrm{N}\right.$ and $154^{\circ} 59^{\prime} \mathrm{E}-165^{\circ} 01^{\prime} \mathrm{W}$ ) in 2013 , and 262 fish from 11 sampling stations $\left(39^{\circ} 43-44^{\circ} 29^{\prime} \mathrm{N}\right.$ and $\left.158^{\circ} 58^{\prime} \mathrm{E}-165^{\circ} 00^{\prime} \mathrm{W}\right)$ in 2014, were examined (Table 2, Fig. 1).

Immediately after capture, one of a fish's two ovaries was extracted and fixed for 3-7 days in Bouin's solution, then transferred to $70 \%$ ethanol. Fish bodies were frozen, then transported to the laboratory where their BL (to nearest $0.1 \mathrm{~cm}$ ) was measured. Fish were aged and their ROA measured. Because of right otolith abnormality, the left otolith of 10 fish (seven in 2013 and three in 2014) was examined; ROAs of these otoliths were not measured.

\section{Ovarian histology}

Two serial histological (using standard paraffin techniques) sections of 8-10 $\mu \mathrm{m}$ were taken from the mid-part of each ovary. The first section was stained with VB solution (Wako Pure Chemical Industries, Osaka, Japan) and unoxidized Azocarmine G solution (Wako Pure Chemical Industries) to enable ovarian arteriole analysis (Suyama et al. 2016a). However, as VB-positive arterioles are often not detected in spawning fish (Suyama et al. 2016a), the second section was stained with Mayer's hematoxylin and eosin-Y (H\&E) to examine oocyte developmental stage and the presence of atretic oocytes and/or POF (Hunter and Macewicz 1985a, b).

Stained arterioles were observed under a microscope at maximum magnifications of $400 \times$ or $1000 \times$. In the first slide, numbers of deeply and clearly stained VB-positive arterioles were counted across complete cross-sections. In the second slide, individuals with yolked oocytes (yolkaccumulating oocytes to ovulated stages), $\mathrm{POF}$ and/or alpha and beta stages of atresia from yolked oocytes, were identified as either spawning or recently spawned fish (Hunter and Macewicz 1985a, b). 
Table 1 Pacific saury (PS, Cololabis saira) sampling records and comparison of body length (BL), radius of annual ring (ROA) of otolith, and ovary weight (OW)

\begin{tabular}{|c|c|c|c|c|c|c|c|}
\hline & \multicolumn{7}{|l|}{ Area } \\
\hline & $140-150^{\circ} \mathrm{E}$ & $150-160^{\circ} \mathrm{E}$ & $160-170^{\circ} \mathrm{E}$ & $170^{\circ} \mathrm{E}-180^{\circ}$ & $180-170^{\circ} \mathrm{W}$ & $170-164^{\circ} \mathrm{W}$ & All areas \\
\hline \multicolumn{8}{|l|}{2013} \\
\hline Survey duration & 8-12 July & 23 June-2 July & 12-22 June & 17-28 June & 26 June-7 July & 4-13 July & 12 June-13 July \\
\hline$N$ stations & 15 & 24 & 21 & 22 & 18 & 25 & 125 \\
\hline$N$ stations PS caught & 4 & 9 & 10 & 15 & 12 & 15 & 65 \\
\hline$N$ PS caught & 66 & 7451 & 11,487 & 10,738 & 11,398 & 13,727 & 54,867 \\
\hline Estimated $N$ of age- 0 & 43 & 3999 & 5 & 1039 & 4282 & 7874 & 17,245 \\
\hline Estimated $N$ of age- 1 & 24 & 3452 & 11,482 & 9699 & 7114 & 5853 & 37,623 \\
\hline Percentages of age-1 $(\%)$ & $35.6 \%$ & $46.3 \%$ & $100.0 \%$ & $90.3 \%$ & $62.4 \%$ & $42.6 \%$ & $68.6 \%$ \\
\hline \multicolumn{8}{|c|}{ Measured BL $(\mathrm{cm})$ of age-1 } \\
\hline$N$ & 22 & 385 & 700 & 1080 & 510 & 388 & 3063 \\
\hline Mean (SD) & $30.2(0.8)$ & $29.6(0.9)$ & $29.1(1.1)$ & $28.8(1.2)$ & $28.7(1.5)$ & $29.5(1.4)$ & $29.0(1.3)$ \\
\hline Min-max & $28.7-31.2$ & $26.7-31.7$ & $25.7-32.4$ & $24.7-32.2$ & $25.9-33.3$ & $26.1-33.1$ & $24.7-33.3$ \\
\hline \multicolumn{8}{|c|}{$\mathrm{BL}(\mathrm{cm})$ for histological observations of age- 1} \\
\hline$N$ & 0 & 60 & 95 & 167 & 74 & 91 & 487 \\
\hline Mean (SD) & - & $30.2(0.95)$ & $29.2(1.24)$ & $28.6(1.26)$ & $28.9(1.48)$ & $29.8(1.38)$ & $29.2(1.39)$ \\
\hline Min-max & - & $27.8-31.7$ & $26.5-31.9$ & $25.7-31.8$ & $25.9-32.1$ & $26.4-32.9$ & $25.7-32.9$ \\
\hline \multicolumn{8}{|c|}{ Measured ROA (mm) of age-1 } \\
\hline$N$ & 22 & 381 & 699 & 1077 & 510 & 388 & 3055 \\
\hline Mean (SD) & $0.57(0.05)$ & $0.57(0.06)$ & $0.56(0.06)$ & $0.55(0.06)$ & $0.53(0.05)$ & $0.51(0.06)$ & $0.55(0.06)$ \\
\hline Min-max & $0.47-0.68$ & $0.41-0.82$ & $0.36-0.76$ & $0.40-0.79$ & $0.39-0.66$ & $0.36-0.73$ & $0.36-0.82$ \\
\hline \multicolumn{8}{|c|}{ ROA (mm) for histological observations of age- 1} \\
\hline$N$ & 0 & 56 & 95 & 164 & 74 & 91 & 480 \\
\hline Mean (SD) & - & $0.58(0.07)$ & $0.57(0.06)$ & $0.54(0.06)$ & $0.52(0.06)$ & $0.52(0.06)$ & $0.55(0.06)$ \\
\hline Min-max & - & $0.42-0.82$ & $0.36-0.70$ & $0.41-0.68$ & $0.40-0.65$ & $0.38-0.73$ & $0.36-0.82$ \\
\hline \multicolumn{8}{|l|}{ Measured OW $(\mathrm{g})$ of age- 1} \\
\hline$N$ & 10 & 218 & 381 & 618 & 302 & 232 & 1761 \\
\hline Mean (SD) & $4.11(3.02)$ & $0.67(0.24)$ & $0.54(0.24)$ & $0.45(0.17)$ & $0.46(0.44)$ & $0.55(0.52)$ & $0.53(0.47)$ \\
\hline Min-max & $0.83-9.28$ & $0.25-1.65$ & $0.11-1.96$ & $0.07-1.38$ & $0.17-6.02$ & $0.04-3.28$ & $0.04-9.28$ \\
\hline \multicolumn{8}{|c|}{ OW (g) for histological observations of age-1 } \\
\hline$N$ & 0 & 60 & 95 & 167 & 74 & 91 & 487 \\
\hline Mean (SD) & - & $0.67(0.24)$ & $0.44(0.19)$ & $0.41(0.16)$ & $0.54(0.74)$ & $0.61(0.62)$ & $0.50(0.43)$ \\
\hline Min-max & - & $0.29-1.65$ & $0.11-1.08$ & $0.21-1.38$ & $0.20-6.02$ & $0.10-3.28$ & $0.10-6.02$ \\
\hline \multicolumn{8}{|l|}{2014} \\
\hline Survey duration & 13-15 July & 27 June-5 July & 12-26 June & 15 June-16 July & 5-11 July & 25 June-3 July & 12 June-15 July \\
\hline$N$ stations & 8 & 23 & 21 & 31 & 18 & 20 & 121 \\
\hline$N$ stations PS caught & 0 & 12 & 14 & 19 & 12 & 12 & 69 \\
\hline$N$ PS caught & 0 & 2858 & 11,195 & 16,141 & 5854 & 13,984 & 50,032 \\
\hline Estimated $N$ of age- 0 & 0 & 315 & 379 & 5601 & 5359 & 13,597 & 25,251 \\
\hline Estimated $N$ of age- 1 & 0 & 2543 & 10,816 & 10,540 & 495 & 387 & 24,781 \\
\hline Percentages of age-1 $(\%)$ & - & $89.0 \%$ & $96.6 \%$ & $65.3 \%$ & $8.5 \%$ & $2.8 \%$ & $49.5 \%$ \\
\hline \multicolumn{8}{|c|}{ Measured BL $(\mathrm{cm})$ of age-1 } \\
\hline$N$ & 0 & 565 & 553 & 815 & 202 & 92 & 2227 \\
\hline Mean (SD) & - & $30.4(0.91)$ & $29.7(0.99)$ & $29.4(1.08)$ & $30.2(1.11)$ & $30.2(1.20)$ & $29.8(1.1)$ \\
\hline Min-max & - & $27.6-33.0$ & $27.1-32.9$ & $26.3-33.0$ & $27.7-33.2$ & $28.0-34.7$ & $26.3-34.7$ \\
\hline \multicolumn{8}{|c|}{$\mathrm{BL}(\mathrm{cm})$ for histological observations of age- 1} \\
\hline$N$ & 0 & 20 & 60 & 86 & 31 & 40 & 237 \\
\hline Mean (SD) & - & $30.6(1.05)$ & $29.8(0.99)$ & $29.6(0.98)$ & $29.9(1.07)$ & $30.7(1.27)$ & $30.0(1.13)$ \\
\hline Min-max & - & $28.5-32.7$ & 27.9-32.9 & $27.5-32.5$ & $28.4-32.6$ & $28.5-34.7$ & $27.5-34.7$ \\
\hline
\end{tabular}


Table 1 (continued)

Area

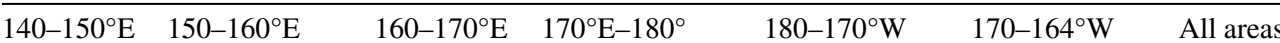

Measured ROA (mm) of age-1

$N$

Mean (SD)

$0 \quad 565$

$0.60(0.06)$

552

813

$0.59(0.06) \quad 0.56(0.06)$

202

91

2223

Min-max

- $\quad 0.40-0.81$

$0.40-0.79 \quad 0.35-0.77$

$0.55(0.06)$

$0.54(0.06)$

$0.58(0.06)$

ROA (mm) for histological observations of age-1

$\begin{array}{llllllll}N & 0 & 20 & 60 & 84 & 31 & 39 & 234 \\ \text { Mean (SD) } & - & 0.61(0.08) & 0.59(0.06) & 0.57(0.05) & 0.53(0.06) & 0.55(0.06) & 0.57(0.06) \\ \text { Min-max } & - & 0.45-0.80 & 0.48-0.71 & 0.48-0.75 & 0.41-0.65 & 0.38-0.69 & 0.38-0.80\end{array}$

Measured OW (g) of age-1

$\begin{array}{llllllll}N & 0 & 295 & 327 & 435 & 92 & 70 & 1219 \\ \text { Mean (SD) } & - & 0.73(0.37) & 0.57(0.21) & 0.60(0.59) & 0.75(0.57) & 0.92(1.00) & 0.65(0.51) \\ \text { Min-max } & - & 0.24-4.05 & 0.20-2.14 & 0.20-7.12 & 0.17-4.02 & 0.30-6.55 & 0.17-7.12\end{array}$

OW (g) for histological observations of age-1

\begin{tabular}{llllllll}
$N$ & 0 & 20 & 60 & 86 & 31 & 40 & 237 \\
Mean (SD) & - & $0.89(0.33)$ & $0.56(0.23)$ & $0.54(0.28)$ & $0.46(0.21)$ & $0.96(0.84)$ & $0.64(0.45)$ \\
Min-max & - & $0.54-1.85$ & $0.20-1.81$ & $0.20-1.90$ & $0.26-1.38$ & $0.34-4.00$ & $0.20-4.00$ \\
\hline
\end{tabular}

\section{3}

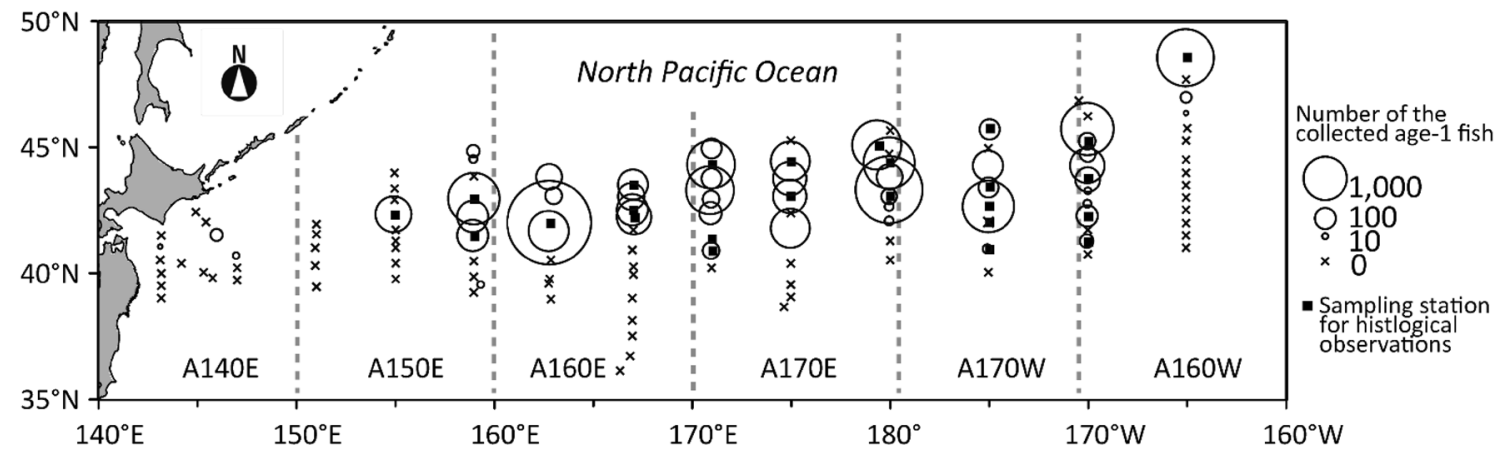

\section{4}

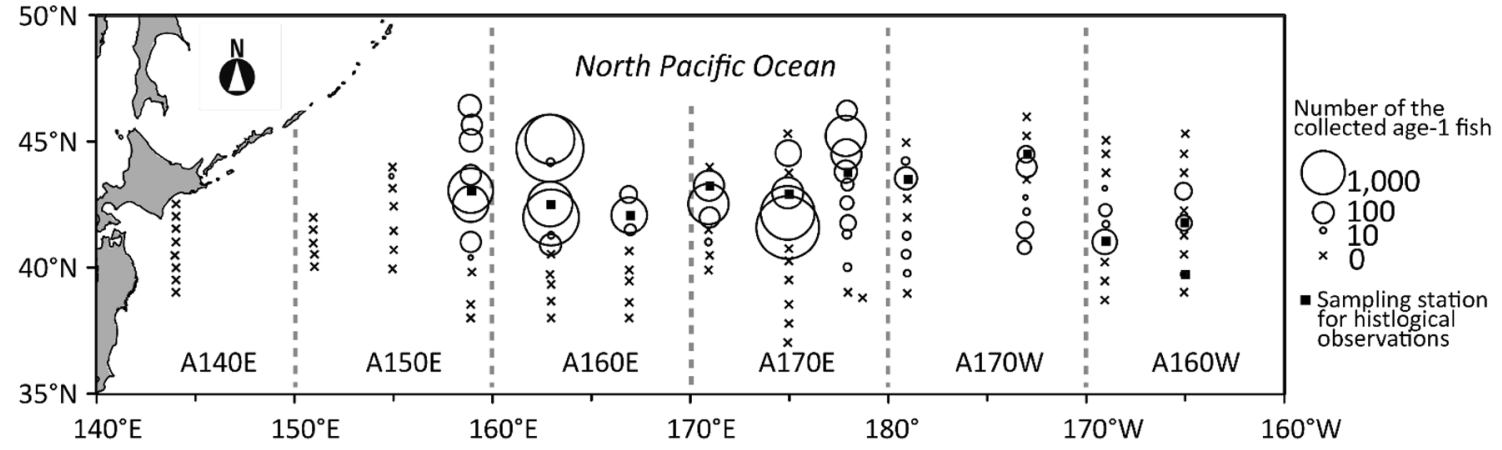

Fig. 1 Sample stations and numbers of age-1 Pacific saury Cololabis saira in the North Pacific off Japan, June and July, 2013 and 2014.

White circles and crosses depict the numbers of fish caught; solid squares depict sampling stations for histological observations of ovarian arterioles and maturation stages 


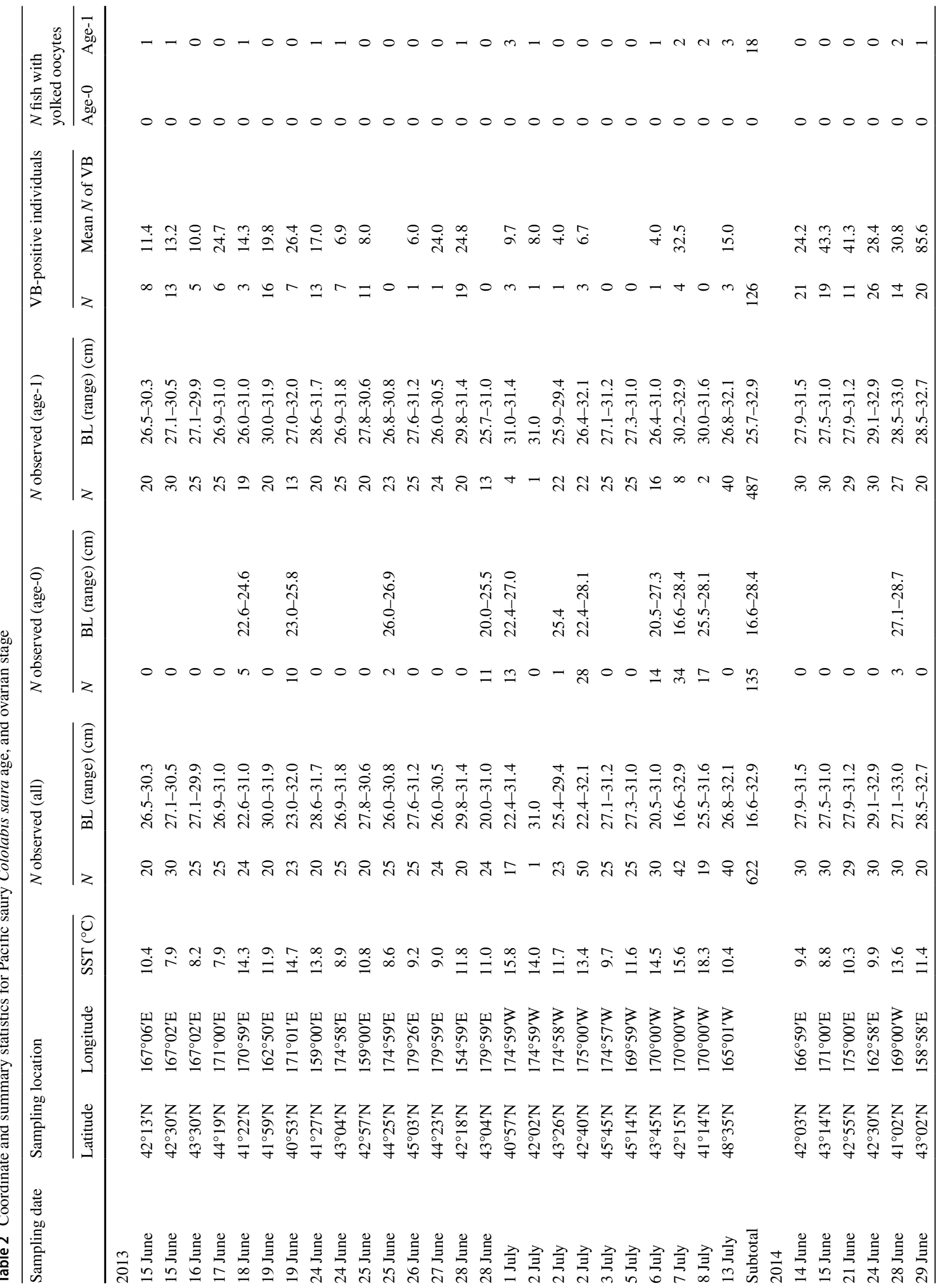




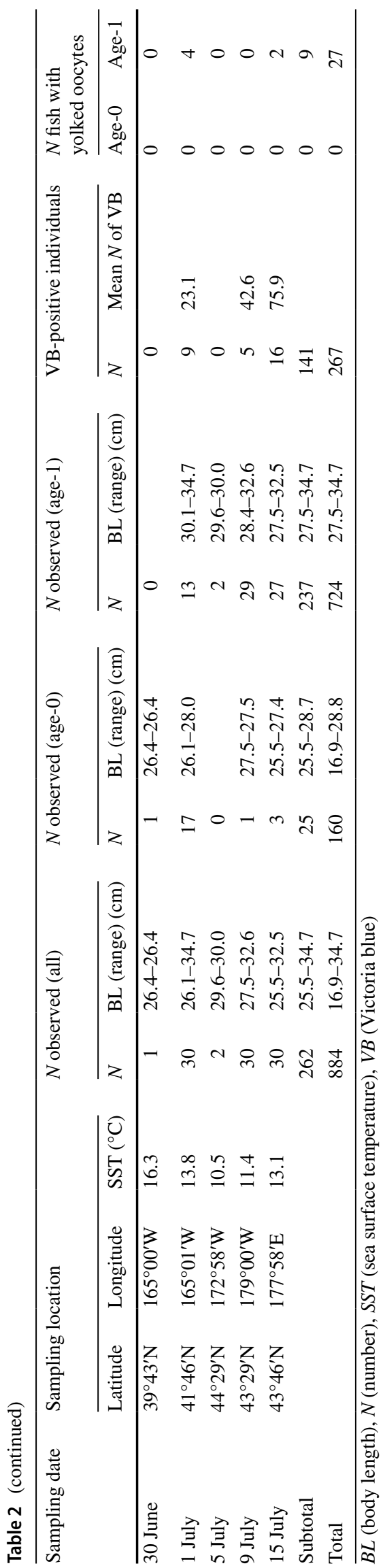

\section{Statistical analysis}

We used a generalized linear model where the $i$ th $(i=1, \ldots, N$; where $N$ is total number of age- 1 fish observed) occurrence of a fish with VB-positive arterioles was treated as a response variable $\left(y_{i}=1\right.$ if $i$ th fish has VB-positive arteriole, otherwise $y_{i}=0$ ). The response variable follows the Bernoulli distribution of probability $p_{i}$, where longitude (LONG), latitude (LAT), BL, ROA of age-1 fish, year (2013 or 2014), sea surface temperature (SST), and elapsed days from a starting date of the survey (DAY), were used as fixed effect terms. Here, the starting date of the survey was set as 14 June (i.e., elapsed days for 15 June 2013 and 14 June 2014 were treated as two and one, respectively). The model formula is: $y_{i} \sim \operatorname{Bernoulli}\left(p_{i}\right)$,

$$
\begin{aligned}
\operatorname{logit}\left(p_{i}\right) & =\alpha+\beta_{1} \mathrm{LONG}_{i}+\beta_{2} \mathrm{LAT}+\beta_{3} \mathrm{ROA}_{i} \\
& +\beta_{4} \mathrm{BL}_{i}+\beta_{5} z_{i}+\beta_{6} \mathrm{SST}_{i}+\beta_{7} \mathrm{DAY}_{i}
\end{aligned}
$$

where $\alpha$ and $\beta_{1-7}$ are parameters to be estimated. Year was treated as a categorical variable $\left(z_{i}=0\right.$ if $i$ th year $=2013$, $z_{i}=1$ otherwise). Longitude and latitude were treated as continuous variables. Westings were converted to eastings (e.g., $170^{\circ} \mathrm{W}$ was converted to $190^{\circ} \mathrm{E}$ ). Because of high collinearity, interaction terms among the seven fixed terms were not included in the model. Model selection using Akaike information criterion (AIC) (Akaike 1974) was carried out. The statistical software R (https://www.R-project.org/. Accessed 27 June 2018) and a function "glm" were used.

Differences in mean ROA between groups (e.g., comparison between ROA of fish with and without VB-positive arterioles, or ROA of fish with VB-positive arterioles, in 2013 and 2014) were assessed using analysis of variance followed by Tukey's multiple comparisons tests. Significant differences were determined at the 5\% level.

\section{Results}

\section{Age composition and BL range of age-1 fish}

A total 54,813 Pacific saury were caught at 64 of 124 stations $\left(39^{\circ} 04-48^{\circ} 35^{\prime} \mathrm{N}\right.$ and $\left.143^{\circ} 10^{\prime} \mathrm{E}-164^{\circ} 58^{\prime} \mathrm{W}\right)$ in 2013 , and 50,032 individuals at 69 out of 121 sampling stations $\left(37^{\circ} 01-46^{\circ} 24^{\prime} \mathrm{N}\right.$ and $\left.154^{\circ} 59^{\prime} \mathrm{E}-165^{\circ} 00^{\prime} \mathrm{W}\right)$ in 2014 . Of these, $37,589(68.6 \%)$ were estimated age-1 fish in 2013, and $24,781(49.5 \%)$ in 2014. The minimum BL of age- 1 fish was $24.7 \mathrm{~cm}$ in 2013, and $26.3 \mathrm{~cm}$ in 2014 (Table 1, Fig. 2).

Of 622 fish in 2013 from which ovaries were examined, 487 were classified as age- 1 ; BL ranged $25.7-32.9 \mathrm{~cm}$. The remaining fish (135 individuals; BL 16.9-28.8 cm) were classified age-0. Of the 262 fish in 2014 for which ovaries 


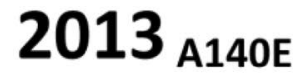

A150E

A160E

A170E

A170W

A160W
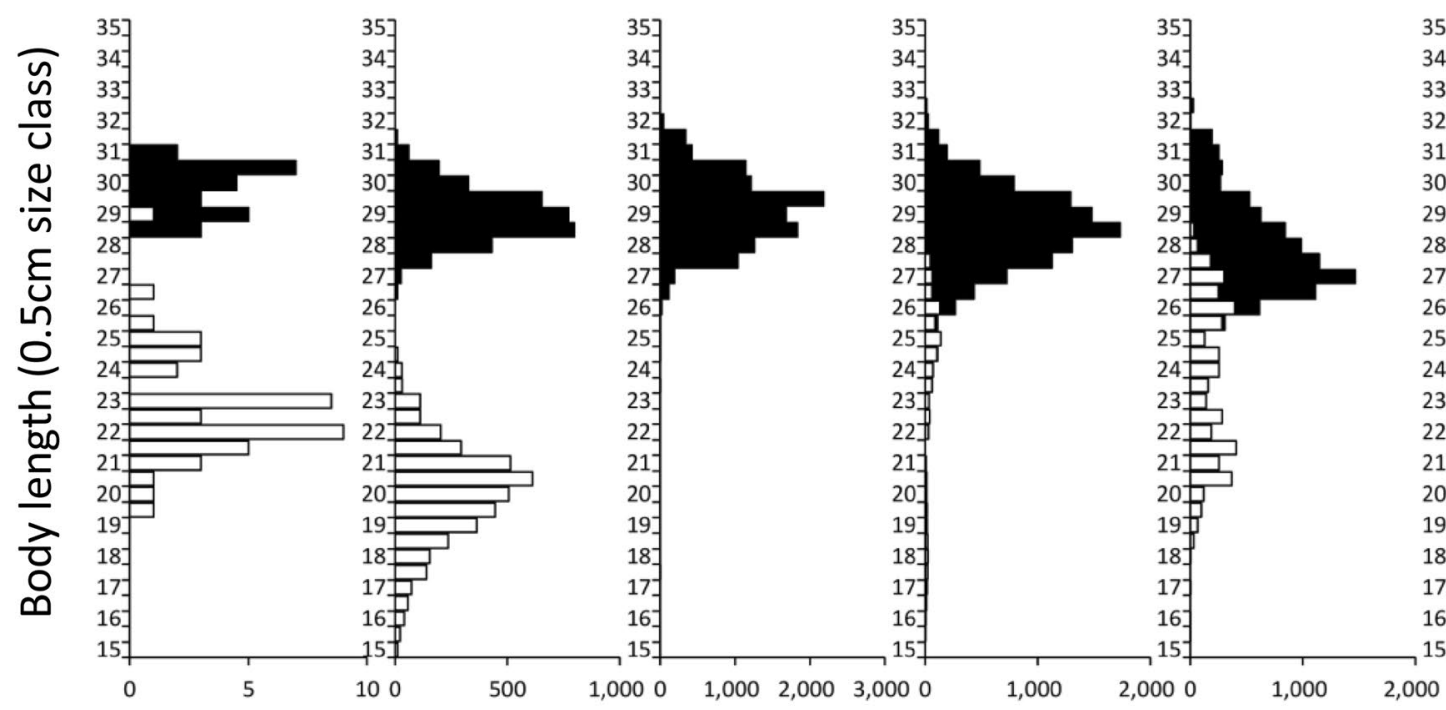

Age-0 fish

Age-1 fish

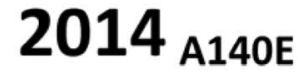

A150E

A160E

A170E

A170W

A160W
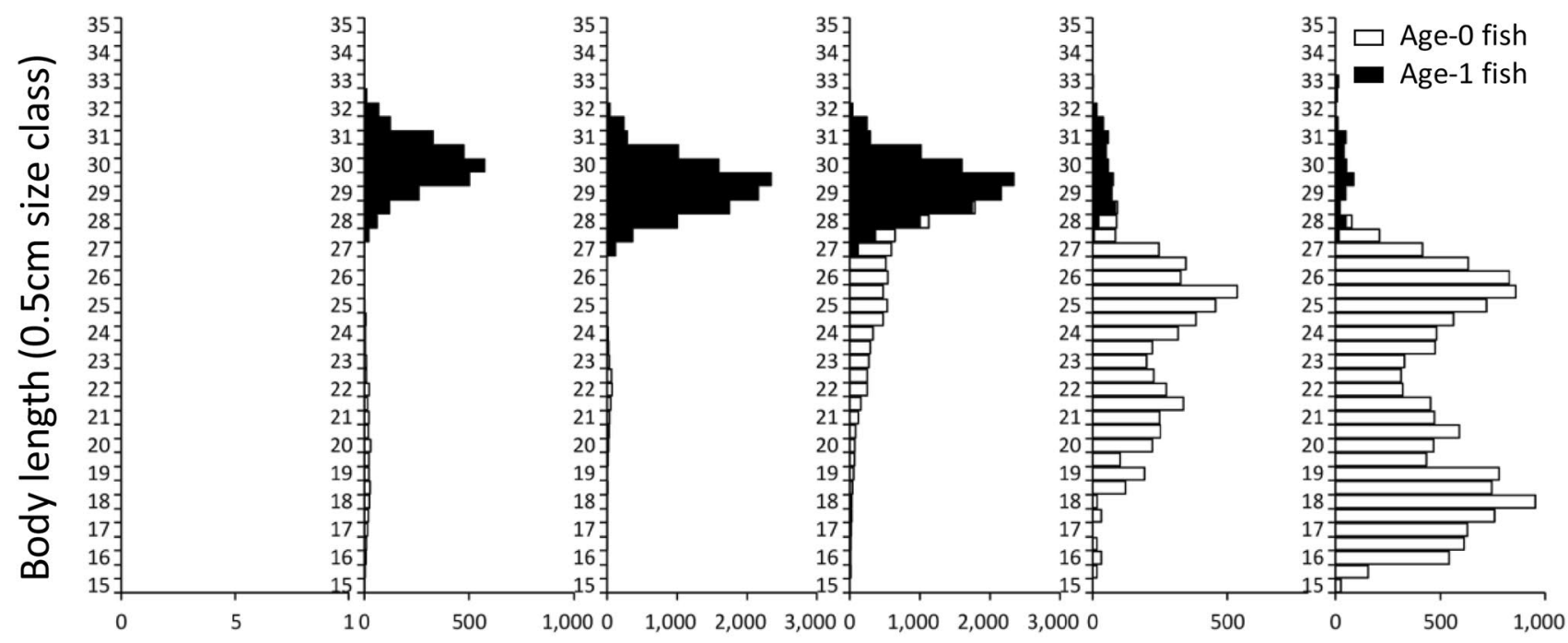

\section{Number of fish caught in each $0.5 \mathrm{~cm}$ size class}

Fig. 2 Size compositions of Pacific saury Cololabis saira collected by surface trawl in $10^{\circ}$ longitudinal areas in June and July in 2013 (upper) and 2014 (lower)

were examined, 237 of them were classified as age-1; BL ranged $27.5-34.7 \mathrm{~cm}$. The remaining fish $(25$ individuals; BL $25.5-28.7 \mathrm{~cm}$ ) were classified as age-0.

\section{Occurrence of VB-positive arterioles}

Whereas no age-0 fish had VB-positive arterioles, 126 (25.9\%) of 487 age-1 fish in 2013 (BL 26.4-32.9 cm) and
141 (59.5\%) of 237 age-1 fish in 2014 (BL 27.9-34.7 cm), did. BL in fish lacking VB-positive arterioles ranged $25.7-31.7 \mathrm{~cm}$ in 2013 and $27.5-31.9 \mathrm{~cm}$ in 2014 (Table 2).

The percentages of age- 1 fish with VB-positive arteriolesin 2013 were highest at $150^{\circ} \mathrm{E}(71.7 \%)$, with $44.2 \%$, $15.0 \%, 10.8 \%$, and $8.8 \%$ in areas A160E, A170E, A170 W, and A160 W, respectively. All age-1 fish collected in 2014 had VB-positive arterioles in area $\mathrm{A} 150 \mathrm{E}$, but the ratio 


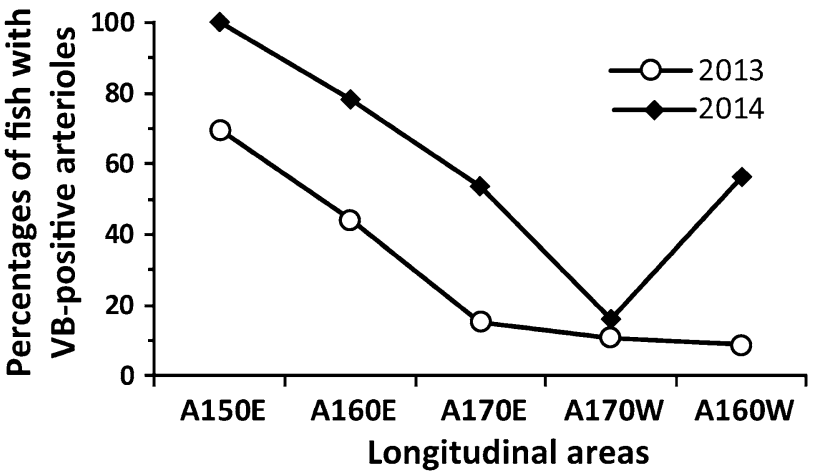

Fig. 3 Percentages of Pacific saury Cololabis saira with Victoria blue (VB)-positive arterioles in each longitudinal area in 2013 and 2014 decreased in eastern areas $(78.3 \%, 53.5 \%$, and $16.1 \%$ at A160E, A170E, and A170 W, respectively). Exceptionally, $57.5 \%$ of fish had VB-positive arterioles in area A $160 \mathrm{~W}$, which was higher than values in areas A160E, A170E, or A170 W (Fig. 3).

\section{Occurrence of yolked oocytes, POF and atresia from yolked oocytes}

No age-0 fish collected in 2013 or 2014, caught in June or July, had yolked oocytes, POF, or atresia from yolked oocytes. A minority of age-1 fish [18 (3.7\%) in 2013 and $9(3.8 \%)$ in 2014 ] had yolked oocytes, atretic oocytes that originated from yolked oocytes, and/or POF (Tables 2, 3). Seven of 18 fish in 2013 and one of nine fish in 2014 lacked VB-positive arterioles, though they had yolked oocytes and/ or atretic oocytes originating from yolked oocytes. All but one of these fish were sampled in the western area. POF

Table 3 Fish with yolked oocytes and/or atretic oocytes originating from yolked oocytes

\begin{tabular}{|c|c|c|c|c|c|c|c|c|c|c|c|}
\hline \multirow[t]{2}{*}{ Individual number } & \multirow[t]{2}{*}{ Year } & \multicolumn{4}{|c|}{ Sampling location } & \multirow[t]{2}{*}{$\mathrm{BL}(\mathrm{cm})$} & \multirow[t]{2}{*}{ OW (g) } & \multirow[t]{2}{*}{$\mathrm{N}$ of VB-P } & \multirow{2}{*}{$\begin{array}{l}\text { Yolked } \\
\text { Oocyte }\end{array}$} & \multirow{2}{*}{$\begin{array}{l}\text { Atretic Oocyte } \\
\text { from yolked } \\
\text { oocyte }\end{array}$} & \multirow[t]{2}{*}{$\mathrm{POF}$} \\
\hline & & Sampling date & Latitude & Longitude & $\operatorname{SST}\left({ }^{\circ} \mathrm{C}\right)$ & & & & & & \\
\hline 13611 & 2013 & 15 June & $42^{\circ} 13^{\prime} \mathrm{N}$ & $167^{\circ} 06^{\prime} \mathrm{E}$ & 10.4 & 28.6 & 1.02 & 10 & - & + & - \\
\hline 13639 & 2013 & 15 June & $42^{\circ} 30^{\prime} \mathrm{N}$ & $167^{\circ} 02^{\prime} \mathrm{E}$ & 7.9 & 29.5 & 0.70 & 36 & - & + & - \\
\hline 13675 & 2013 & 18 June & $41^{\circ} 22^{\prime} \mathrm{N}$ & $170^{\circ} 59^{\prime} \mathrm{E}$ & 14.3 & 31 & 1.38 & 26 & - & + & - \\
\hline 13727 & 2013 & 24 June & $43^{\circ} 04^{\prime} \mathrm{N}$ & $174^{\circ} 58^{\prime} \mathrm{E}$ & 8.9 & 29.1 & 1.05 & 8 & - & + & - \\
\hline 13124 & 2013 & 24 June & $41^{\circ} 27^{\prime} \mathrm{N}$ & $159^{\circ} 00^{\prime} \mathrm{E}$ & 13.8 & 30.1 & 1.65 & 2 & + & + & - \\
\hline 13072 & 2013 & 28 June & $42^{\circ} 18^{\prime} \mathrm{N}$ & $154^{\circ} 59^{\prime} \mathrm{E}$ & 11.8 & 30 & 0.63 & 0 & - & + & - \\
\hline 13854 & 2013 & 1 July & $40^{\circ} 57^{\prime} \mathrm{N}$ & $174^{\circ} 59^{\prime} \mathrm{W}$ & 15.8 & 31.1 & 6.02 & 0 & + & + & + \\
\hline 13856 & 2013 & 1 July & $40^{\circ} 57^{\prime} \mathrm{N}$ & $174^{\circ} 59^{\prime} \mathrm{W}$ & 15.8 & 31.4 & 1.30 & 4 & + & + & - \\
\hline 13857 & 2013 & 1 July & $40^{\circ} 57^{\prime} \mathrm{N}$ & $174^{\circ} 59^{\prime} \mathrm{W}$ & 15.8 & 31.4 & 2.74 & 18 & + & + & + \\
\hline 13877 & 2013 & 2 July & $42^{\circ} 02^{\prime} \mathrm{N}$ & $174^{\circ} 59^{\prime} \mathrm{W}$ & 14.0 & 31 & 1.30 & 8 & - & + & - \\
\hline 131024 & 2013 & 6 July & $43^{\circ} 45^{\prime} \mathrm{N}$ & $170^{\circ} 00^{\prime} \mathrm{W}$ & 14.5 & 30.5 & 0.98 & 4 & + & + & - \\
\hline 131051 & 2013 & 7 July & $42^{\circ} 15^{\prime} \mathrm{N}$ & $170^{\circ} 00^{\prime} \mathrm{W}$ & 15.6 & 32.9 & 1.59 & 3 & + & + & - \\
\hline 131052 & 2013 & 7 July & $42^{\circ} 15^{\prime} \mathrm{N}$ & $170^{\circ} 00^{\prime} \mathrm{W}$ & 15.6 & 31.5 & 3.08 & 0 & + & + & - \\
\hline 131031 & 2013 & 8 July & $41^{\circ} 14^{\prime} \mathrm{N}$ & $170^{\circ} 00^{\prime} \mathrm{W}$ & 18.3 & 30 & 2.66 & 0 & + & + & + \\
\hline 131040 & 2013 & 8 July & $41^{\circ} 14^{\prime} \mathrm{N}$ & $170^{\circ} 00^{\prime} \mathrm{W}$ & 18.3 & 31.6 & 2.64 & 0 & + & + & - \\
\hline 131102 & 2013 & 13 July & $48^{\circ} 35^{\prime} \mathrm{N}$ & $165^{\circ} 01^{\prime} \mathrm{W}$ & 10.4 & 31 & 1.40 & 0 & + & + & + \\
\hline 131109 & 2013 & 13 July & $48^{\circ} 35^{\prime} \mathrm{N}$ & $165^{\circ} 01^{\prime} \mathrm{W}$ & 10.4 & 31.6 & 3.28 & 0 & + & + & + \\
\hline 131134 & 2013 & 13 July & $48^{\circ} 35^{\prime} \mathrm{N}$ & $165^{\circ} 01^{\prime} \mathrm{W}$ & 10.4 & 31 & 3.00 & 34 & + & + & - \\
\hline 14071 & 2014 & 29 June & $43^{\circ} 02^{\prime} \mathrm{N}$ & $158^{\circ} 58^{\prime} \mathrm{E}$ & 11.4 & 32 & 1.85 & 237 & + & + & - \\
\hline 14382 & 2014 & 28 June & $41^{\circ} 02^{\prime} \mathrm{N}$ & $169^{\circ} 00^{\prime} \mathrm{W}$ & 13.6 & 31.4 & 1.32 & 42 & + & + & - \\
\hline 14392 & 2014 & 28 June & $41^{\circ} 02^{\prime} \mathrm{N}$ & $169^{\circ} 00^{\prime} \mathrm{W}$ & 13.6 & 31.3 & 2.20 & 7 & + & + & - \\
\hline 14452 & 2014 & 1 July & $41^{\circ} 46^{\prime} \mathrm{N}$ & $165^{\circ} 01^{\prime} \mathrm{W}$ & 13.8 & 34.7 & 4.00 & 53 & + & + & - \\
\hline 14457 & 2014 & 1 July & $41^{\circ} 46^{\prime} \mathrm{N}$ & $165^{\circ} 01^{\prime} \mathrm{W}$ & 13.8 & 30.8 & 3.20 & 0 & + & - & + \\
\hline 14465 & 2014 & 1 July & $41^{\circ} 46^{\prime} \mathrm{N}$ & $165^{\circ} 01^{\prime} \mathrm{W}$ & 13.8 & 32.3 & 3.24 & 3 & + & + & - \\
\hline 14470 & 2014 & 1 July & $41^{\circ} 46^{\prime} \mathrm{N}$ & $165^{\circ} 01^{\prime} \mathrm{W}$ & 13.8 & 31.2 & 1.28 & 11 & - & + & - \\
\hline 14585 & 2014 & 15 July & $43^{\circ} 46^{\prime} \mathrm{N}$ & $177^{\circ} 58^{\prime} \mathrm{E}$ & 13.1 & 29 & 1.90 & 83 & + & + & - \\
\hline 14595 & 2014 & 15 July & $43^{\circ} 46^{\prime} \mathrm{N}$ & $177^{\circ} 58^{\prime} \mathrm{E}$ & 13.1 & 32.5 & 1.84 & 92 & - & + & - \\
\hline
\end{tabular}

$B L$ body length, $O W$ ovary weight, $N$ of $V B-P$ detected number of VB-positive arterioles, $P O F$ post ovulate follicle, present (+) or absent ( - ) 
Fig. 4 Relationship between the mean radius $( \pm \mathrm{SD})$ of the annual ring (ROA) in Pacific saury Cololabis saira otoliths, and incidence of Victoria blue (VB)-positive and VB-negative ovarian arterioles, for different latitudinal (a, b) and longitudinal (c, d) areas, and SST (e, f), off the coast of Japan in 2013 (left) and 2014 (right). Numbers denote numbers of fish analyzed

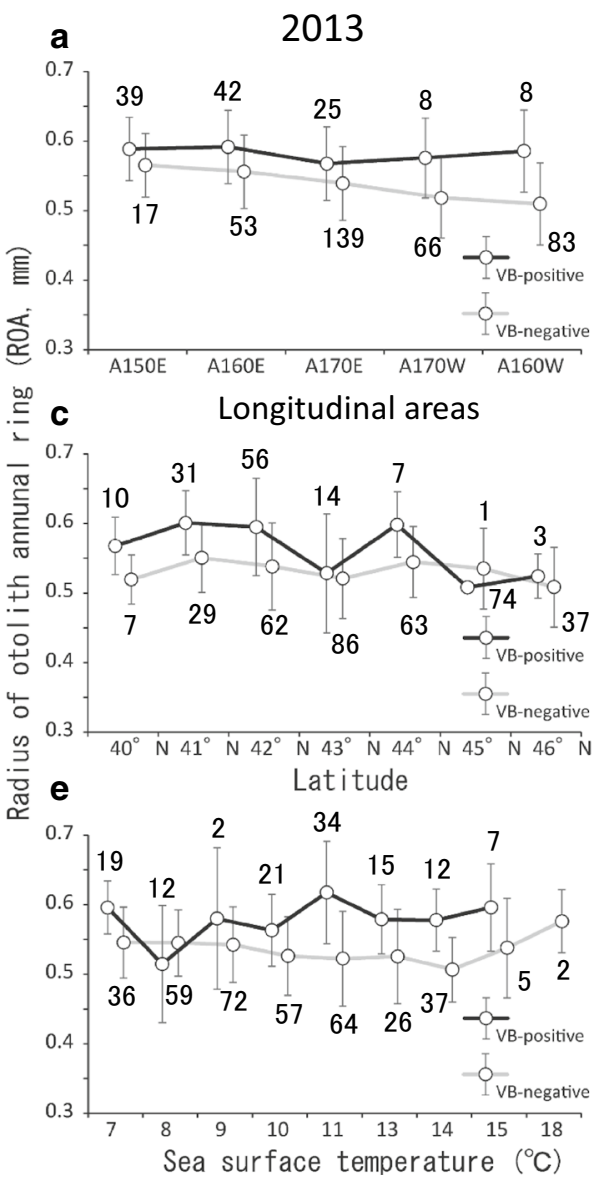

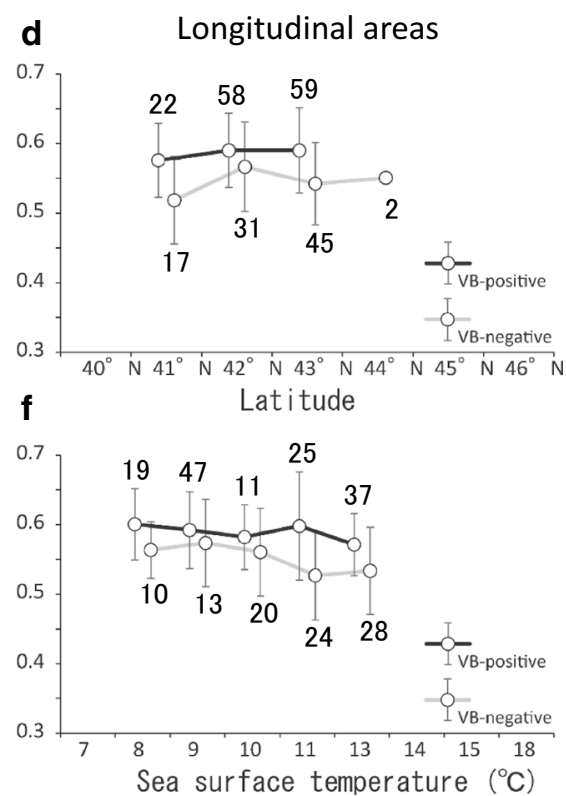

Table 4 Estimated parameters from GLM

\begin{tabular}{llrlc}
\hline Variables & Parameters & Estimates & SE & $P$ value \\
\hline Intercept & $\alpha$ & -0.073 & 4.956 & 0.988 \\
LONG & $\beta_{1}$ & -0.085 & 0.012 & $<0.01$ \\
LAT & $\beta_{2}$ & -0.374 & 0.091 & $<0.01$ \\
ROA & $\beta_{3}$ & 5.061 & 1.989 & 0.0109 \\
BL & $\beta_{4}$ & 0.921 & 0.106 & $<0.01$ \\
Z & $\beta_{5}$ & 0.997 & 0.220 & $<0.01$ \\
\hline
\end{tabular}

$S E$ standard error

were detected from five individuals in 2013 and one in 2014; all fish had yolk accumulating oocytes.

\section{Geographic variation in percentages of fish with VB-positive arterioles and ROA}

Comparisons of mean ROA in different latitudinal and longitudinal areas and SST, with VB-positive and negative ovarian arterioles are shown in Fig. 4. After model selection, SST and DAY were dropped from the model of best fit. Estimated parameters are shown in Table 4. Calculated $P$ values of all parameters are less than 0.05 . The longitude $\left(\beta_{1}\right)$ estimated regression coefficient is negative, while that of ROA $\left(\beta_{3}\right)$ is positive, meaning the probability of previous spawning increased with a progression west, and as ROA increased. The effect of year $\left(\beta_{5}\right)$ was different from zero $(P<0.05)$, which suggests that its probability differs between years (Table 4, Fig. 4).

\section{ROA comparison between fish with and without VB-positive arterioles}

Mean ROA of all age- 1 fish in $2014[0.57 \pm 0.065 \mathrm{~mm}$ : mean $\pm \mathrm{SD}, 95 \%$ confidence interval $(0.563,0.579)]$ was higher than that for $2013[0.55 \pm 0.06 \mathrm{~mm}(0.540,0.551)]$. Mean ROA of fish with VB-negative arterioles in 2014 $[0.55 \pm 0.06 \mathrm{~mm}(0.533,0.559)]$ was also higher than that for 2013 [0.53 $\pm 0.06 \mathrm{~mm}(0.526,0.538)]$, but differences were not detected in fish with VB-positive arterioles between $2013[0.58 \pm 0.07 \mathrm{~mm}(0.572,0.596)]$ and 2014 $[0.59 \pm 0.06 \mathrm{~mm}(0.578,0.597)]$ (Fig. 5). 


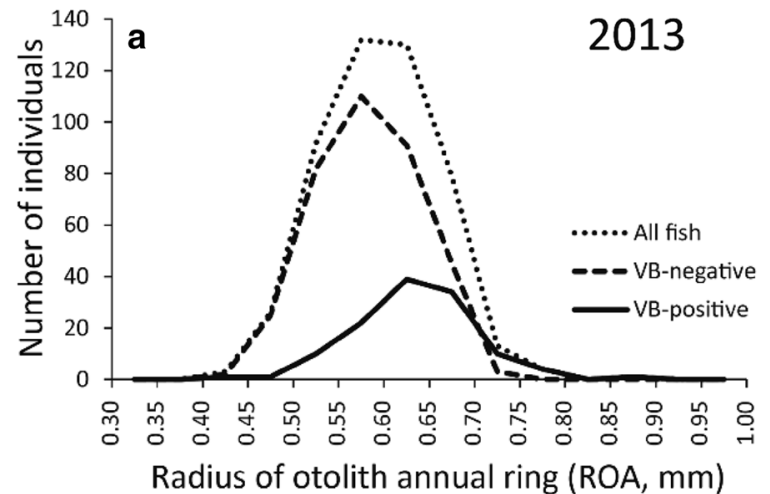

Fig. 5 Size comparison of the radius of the annual ring (ROA) in otoliths for each $0.25-\mathrm{mm}$ size class of Pacific saury Cololabis saira caught in 2013 and 2014. Dotted, solid and broken lines depict all

\section{Discussion}

The incidence of fish with VB-positive arterioles varied according to age and/or collection area. Because variation in the incidence of VB-positive arterioles is caused by differences in the spawning history of an individual fish (Suyama et al. 2016a), the presence of VB-positive arterioles is considered to indicate past spawning experience. As June and July are at the end of the breeding season that commenced the September of the previous year, our results demonstrate age-0 fish do not spawn in the first breeding season in which they hatched. All individuals with VB-positive arterioles are age-1 fish, indicating that some Pacific saury spawn in the second breeding season.

The incidence of fish with VB-positive arterioles also related to ROA. The likelihood of VB-positive arterioles occurring in fish with larger ROA was high, which suggests that $\mathrm{BL}$ at the beginning of the breeding season was important for initiation of maturation in their first year. Therefore, BL composition at the beginning of the breeding season, determined by annual and geographical changes in main hatching periods and/or growth rate, influences the percentage of fish that will spawn (Fig. 6). The difference in ROA between eastern and western survey areas was observed every year; Suyama et al. (2012a) inferred that these differences in the ROA were not caused by differences in hatch period, but by differences in growth rate. We consider that a fish's first spawning in the second breeding season, at an age of almost 1 year, is determined mainly by growth rate during the first year.

During both years, both the percentage of fish with VBpositive arterioles and mean ROA were high in the western area, and low in the eastern area. Mean ROA of all age-1 fish was greater in 2014 than in 2013, and the percentages of fish with VB-positive arterioles were also higher in 2014.

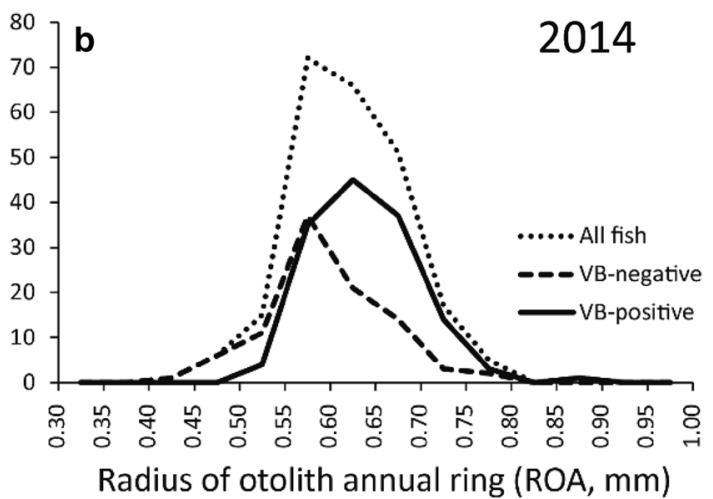

fish, fish with Victoria blue (VB)-positive, and VB-negative ovarian arterioles, respectively

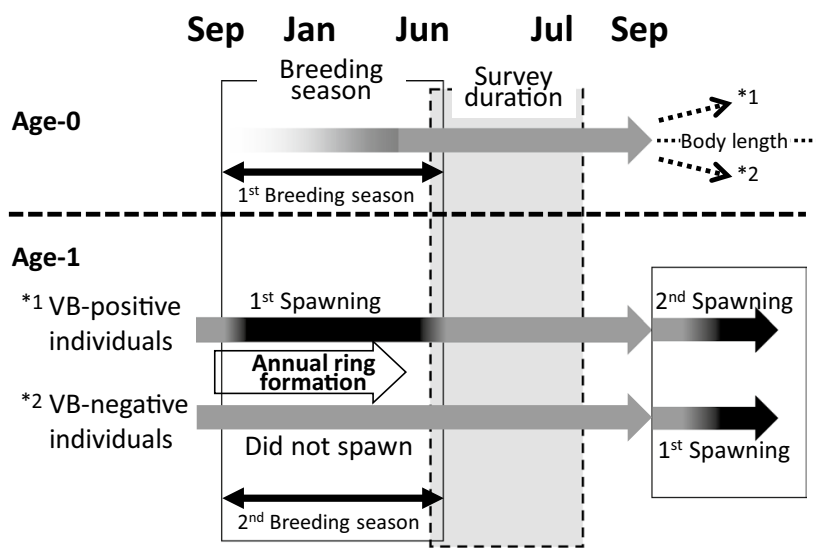

Fig. 6 Schematic of differences in Pacific saury Cololabis saira past spawning experience with and without Victoria blue (VB)-positive ovarian arterioles. "Breeding season" and "spawning period" refer to spawning duration for the population, and spawning duration for each Pacific saury individual, respectively. Breeding season traverses years, from September of one year to June of the following year (square with solid line). Because age-0 fish lack spawning experience in the first breeding season [i.e., from hatching to survey commencement in June or July (gray square with broken line)], they lack VBpositive ovarian arterioles. Some individuals that spawn (thick black band) in the second breeding season appear as age-1 fish with VBpositive ovarian arterioles during the survey. Individuals that do not spawn in the second breeding season lack VB-positive ovarian arterioles

However, the mean ROA of fish with VB-positive arterioles in 2013 and 2014 did not differ significantly, and their 95\% confidence intervals overlapped. Mean ROA was greater in western than eastern areas, as previously reported by Suyama et al. (2012a, b), which suggests geographical differences in maturation rate occur annually. Differences in zooplankton abundance might contribute to high westernlatitude growth rates and the percentage of fish with previous 
spawning experience; however, information on Pacific saury diet is available for coastal areas only (Taka et al. 1982; Odate 1994; Sugisaki and Kurita 2004). Surveys comparing the important species making up the Pacific saury's diet and the relative abundances of these species in the western and eastern parts of the survey area would be helpful for identifying the causes of geographical variation in growth until age at first spawning.

We considered that geographical differences in growth rates of first year fish would be reflected in the different ROA of age- 1 fish, and differences in the percentage of age- 1 fish with spawning experience. Our results suggest that age-0 fish do not migrate widely, though Suyama et al. (2012b) reported most age-1 Pacific saury had migrated from east of $160^{\circ} \mathrm{E}$ to near the coast of Japan from June to December. Larvae and juveniles are abundant in southern waters off Honshu each year during winter (Watanabe and Lo 1989; Takasuka et al. 2014), identifying the importance of this region as a winter spawning ground. Such wide latitudinal migrations have been validated only in age-1 fish (Suyama et al. 2012b, Miyamoto et al. 2019). However, we considered that some larger age- 0 fish in the eastern area might possibly migrate to western areas to spawn; in contrast most age-0 fish that do not spawn in their first year do not migrate west. Consequently, the proportion of mature fish in the second breeding season would increase in western areas, and the percentage of age- 1 fish with spawning experience during the survey would increase. To determine relationships between maturity and migration in age- 0 fish, we should compare otolith growth increments between eastern and western areas, and age-1 fish collected the following year in both areas.

It is unknown how long VB-positive arterioles remain after spawning, though rearing experiments suggest they might persist for 6 months (Suyama et al. 2016a). The breeding season of Pacific saury might continue more than 10 months. We believe that VB-positive arterioles are retained for a long time, probably throughout a current breeding season, because the percentage of individuals with VB-positive arterioles was high in individuals with large ROA. During the migration to southern spawning grounds, larger fish generally arrive first, and start spawning earlier (Fukushima 1979); they would also finish spawning earlier. As the incidence of VB-positive arterioles was high in fish with a large ROA, VB-positive arterioles may persist in individuals that finish spawning early. Furthermore, although individuals with yolked oocytes were common at eastern longitudes, which suggests a spawning delay, the percentage of fish with VB-positive arterioles was low. As such, the reason for low percentages of individuals with VB-positive arterioles in eastern regions might be because of a lack of spawning experience, rather than their disappearance.
The TNFRI has performed stock assessment surveys in the area extending from near the coast of Japan to $165^{\circ} \mathrm{W}$ during June and July since 2003 (Suyama et al. 2016b). Pacific saury abundance off the Japanese coast to $162^{\circ} \mathrm{E}$ decreased suddenly after 2010 from levels experienced from 2003 to 2009, and has remained low on the Japanese coast and offshore regions to the west of $165^{\circ} \mathrm{W}$. Because percentages of spawned age-1 fish were high in western areas, a decrease in their abundance means total maturation rate also decreased in the first year. Annual changes in Pacific saury distributions in June and July might affect total maturation rates in the first year. Further investigation of geographical variation in maturation rates of age-1 Pacific saury is required when abundance levels in western areas increase to those experienced from 2003 to 2009.

Acknowledgements We are grateful to Dr. Toshihide Kitakado, Tokyo University of Marine Science and Technology, and Dr. Yasunori Sakurai, Hakodate Cephalopod Research Center, for their valuable comments. We thank the crews of the T/S Hokuho-maru from the Hokkaido Board of Education and R/V Hokko-maru from the Hokkaido National Fisheries Research Institute, Fisheries Research Agency. We thank Dr. Vijai, State Key Laboratory of Marine Environmental Science, Xiamen University, for reviewing this manuscript. We also thank Junko Momosawa, Naoko Kubo, and Kanae Okabori of TNFRI for measuring fish and otoliths. This study was supported, in part, by the Fisheries Agency of Japan.

Open Access This article is licensed under a Creative Commons Attribution 4.0 International License, which permits use, sharing, adaptation, distribution and reproduction in any medium or format, as long as you give appropriate credit to the original author(s) and the source, provide a link to the Creative Commons licence, and indicate if changes were made. The images or other third party material in this article are included in the article's Creative Commons licence, unless indicated otherwise in a credit line to the material. If material is not included in the article's Creative Commons licence and your intended use is not permitted by statutory regulation or exceeds the permitted use, you will need to obtain permission directly from the copyright holder. To view a copy of this licence, visit http://creativecommons.org/licenses/by/4.0/.

\section{References}

Akaike H (1974) A new look at the statistical model identification. IEEE Trans Autom Control 19:716-723

Barbieri LR, Chittenden ME Jr, Lowerre-Barbieri SK (1994) Maturity, spawning, and ovarian cycle of Atlantic croaker, Micropogonias undulatus, in the Chesapeake Bay and adjacent coastal waters. Fish Bull 92:671-685

Domínguez-Petit R, Anastasopoulou A, Cubillos LA, Gerritsen H, Gonçalves P, Hidalgo M, Kennedy J, Korta M, Marteinsdottir G, Morgado C, Muñoz M, Quincoces I, Sainza M, Thorsen A, Vitale F (2017) Chapter 3: Maturity. In: Domínguez-Petit R, Murua H, Saborido-Rey F, Trippel E (eds) Handbook of applied fisheries reproductive biology for fisheries assessment and management. Digital CSIC Vigo, Pontevedra

Fukushima S (1979) Synoptic analysis of migration and fishing conditions of Pacific saury in the northwest Pacific Ocean. Bull Tohoku Reg Fish Res Lab 41:1-70 
Hatanaka M (1955) Biological studies on the population of the saury, Cololabis saira (Brevoort). Part 1. Reproduction and growth. Tohoku J Agric Res 6:227-269

Hotta H (1960) On the analysis of the population of the Pacific saury (Cololabis saira) based on the scales and the otolith characters, and their growth. Bull Tohoku Reg Fish Res Lab 16:41-64

Huang WB (2010) Comparisons of monthly and geographical variations in abundance and size composition of Pacific saury between the high-seas and coastal fishing grounds in the northwestern Pacific. Fish Sci 76:21-31

Huang WB, Lo NC, Chiu TS, Chen CS (2007) Geographical distribution and abundance of Pacific saury, Cololabis saira (Brevoort) (Scomberesocidae), fishing stocks in the northwestern Pacific in relation to sea temperatures. Zool Stud 46:705-716

Hubbs CL, Wisner RL (1980) Revision of the sauries (Pisces, Scomberesocidae) with descriptions of two new genera and one new species. Fish Bull 77:521-566

Hunter JR, Macewicz BJ (1985a) Measurement of spawning frequency in multiple spawning fishes. NOAA Tech Rep NMFS 36:79-94

Hunter JR, Macewicz BJ (1985b) Rates of atresia in the ovary of captive and wild northern anchovy, Engraulis mordax. Fish Bull 83:119-136

Hunter JR, Macewicz BJ, Sibert JR (1986) The spawning frequency of skipjack tuna, Katsuwonus pelamis, from the South Pacific. Fish Bull 84:895-903

Karlou-Riga C, Panas E (1996) Ovarian atretic rates and sexual maturity of European horse mackerel, Trachurus trachurus (L.), in the Saronikos Gulf (Greece). Fish Bull 94:66-76

Kimura K (1956) The standard length of the Pacific saury, Cololabis saira (Brevoort). Bull Tohoku Reg Fish Res Lab 7:1-11

Kosaka S (2000) Life history of the Pacific saury Cololabis saira in the northwest Pacific and considerations on resource fluctuations based on it. Bull Tohoku Natl Fish Res Inst 63:1-96

Kurita Y (2006) Regional and interannual variations in spawning activity of Pacific saury Cololabis saira during northward migration in spring in the north-western Pacific. J Fish Biol 69:846-859

Kurita Y, Nemoto Y, Oozeki Y, Hayashizaki K, Ida H (2004) Variations in patterns of daily changes in otolith increment widths of $0+$ Pacific saury, Cololabis saira, off Japan by hatch date in relation to the northward feeding migration during spring and summer. Fish Oceanogr 13(Suppl. 1):54-62

Miyamoto H, Suyama S, Vijai D, Kidokoro H, Naya M, Fuji T, Sakai M (2019) Predicting the timing of Pacific saury (Cololabis saira) immigration to Japanese fishing grounds: a new approach based on natural tags in otolith annual rings. Fish Res 209:167-177

Nakaya M, Morioka T, Fukunaga K, Murakami N, Ichikawa T, Sekiya S, Suyama S (2010) Growth and maturation of Pacific saury Cololabis saira under laboratory conditions. Fish Sci 76:45-53

Nemoto Y, Kurita Y, Oozeki Y, Honma T, Hayashizaki K, Ida H (2001) Otolith microstructure of Pacific saury, Cololabis saira. Bull Tohoku Natl Fish Res Inst 64:69-78

Odate K (1994) Zooplankton biomass and its long-term variation in the western North Pacific Ocean, Tohoku Sea Area, Japan. Bull Tohoku Nat Fish Res Inst 56:115-173

Sugama K (1957) Analysis of population of the saury (Cololabis saira Brevoort) on the basis of character of otolith-I. Bull Hokkaido Reg Fish Res Lab 16:1-12

Sugisaki H, Kurita Y (2004) Daily rhythm and seasonal variation of feeding habit of Pacific saury (Cololabis saira) in relation to their migration and oceanographic conditions off Japan. Fish Oceanogr 13(Suppl. 1):63-73

Suyama S (2002) Study on the age, growth, and maturation process of Pacific saury Cololabis saira (Brevoort) in the North Pacific. Bull Fish Res Agen 5:68-113
Suyama S, Sakurai Y, Meguro T, Shimazaki K (1992) Estimation of the age and growth of Pacific saury Cololabis saira in the central North Pacific Ocean determined by otolith daily growth increments. Nippon Suisan Gakkaishi 58:1607-1614

Suyama S, Sakurai Y, Meguro T, Shimazaki K (1996) Maturation and age in days of Pacific saury Cololabis saira (Brevoort) in the central north Pacific Ocean during the summer. Nippon Suisan Gakkaishi 62:361-369

Suyama S, Kurita Y, Ueno Y (2006) Age structure of Pacific saury Cololabis saira based on observations of the hyaline zones in the otolith and length frequency distributions. Fish Sci 72:742-749

Suyama S, Oshima K, Nakagami M, Kawabata A (2011) Seasonal changes in otolith and somatic growth in age-0 Pacific saury Cololabis saira. Fish Sci 77:223-233

Suyama S, Nakagami M, Naya M, Ueno Y (2012a) Comparison of the growth of age-1 Pacific saury Cololabis saira in the western and the central North Pacific. Fish Sci 78:277-285

Suyama S, Nakagami M, Naya M, Ueno Y (2012b) Migration route of Pacific saury Cololabis saira inferred from the otolith hyaline zone. Fish Sci 78:1179-1186

Suyama S, Shimizu A, Isu S, Ozawa H, Morioka T, Nakaya M, Nakagawa T, Murakami N, Ichikawa T, Ueno Y (2016a) Determination of the spawning history of Pacific saury Cololabis saira from rearing experiments: identification of post-spawning fish from histological observations of ovarian arterioles. Fish Sci 82:445-457

Suyama S, Nakagami M, Naya M, Kato Y, Shibata Y, Sakai M, Takeuchi Y (2016b) Stock assessment and evaluation for northwestern Pacific stock of Pacific saury (fiscal year 2015). In: Marine fisheries stock assessment and evaluation for Japanese waters (fiscal year 2015/2016). Fisheries Agency and Fisheries Research Agency of Japan, Tokyo, pp 283-336 (in Japanese)

Taka S, Kitakata M, Wada T (1982) The relations between the saury, Cololabis saira (Brevoort) and the food organisms, especially Calanus plumchrus, in the southeast waters of the Kuril Islands during the summer. Bull Hokkaido Reg Fish Res Lab 47:41-55

Takasuka A, Kuroda H, Okunishi T, Shimizu Y, Hirota Y, Kubota H, Oozeki Y (2014) Occurrence and density of Pacific saury Cololabis saira larvae and juveniles in relation to environmental factors during the winter spawning season in the Kuroshio Current system. Fish Oceanogr 23:304-321

Tseng CT, Su NJ, Sun CL, Punt AE, Yeh SZ, Liu DC, Su WC (2013) Spatial and temporal variability of the Pacific saury (Cololabis saira) distribution in the northwestern Pacific Ocean. ICES J Mar Sci 70:991-999

Tseng CT, Sun C-L, Belkin IM, Yeh SZ, Kuo CL, Liu DC (2014) Sea surface temperature fronts affect distribution of Pacific saury (Cololabis saira) in the northwestern Pacific Ocean. Deep Sea Res II Top Stud Oceanogr 107:15-21

Ueno Y, Suyama S, Nakagami M, Naya M, Sakai M, Kurita Y (2017) Direct estimation of stock abundance of Pacific saury Cololabis saira in the northwestern Pacific Ocean using a mid-water trawl. Fish Sci 83:23-33

Watanabe Y, Lo NC (1989) Larval production and mortality of Pacific saury, Cololabis saira, in the northwestern Pacific Ocean. Fish Bull 87:601-613

Watanabe Y, Butler JL, Mori T (1988) Growth of Pacific saury, Cololabis saira, in the northeastern and northwestern Pacific Ocean. Fish Bull 86:489-498

Publisher's Note Springer Nature remains neutral with regard to jurisdictional claims in published maps and institutional affiliations. 